mycoplasmas and neoplasia in general. The demonstration that in-vitro transformation can be mediated by these organisms $^{19}$ and that cells infected with them may show chromosomal abnormalities ${ }^{2021}$ arouses some suspicion that they might be concerned in the induction of neoplasia.

\section{Acute Respiratory Disease}

Interest in acute respiratory diseases has in some ways become unfashionable. This is partly because many of the illnesses are mild and spontaneous recovery is common, partly because empirical treatment with antibiotics often causes rapid resolution of symptoms, and not least because methods for detection of many of the nonbacterial causative agents have not been available.

Over the last few years new microbiological techniques have opened up the field in a dramatic way, and information about the biological properties of many types of microorganism isolated from human secretions has rapidly accumulated. Perhaps for too long laboratory workers have proceeded in relative isolation from the clinician. Their attitude might be excused when, as in the investigation of viral respiratory disease, a laboratory diagnosis could be made only in retrospect, weeks after the patient had already recovered. But this era now appears to have passed, and so too it seems has the isolation of laboratory from clinical endeavour, to judge by a two-day symposium organized earlier this year by the College of Pathologists.

The proceedings of this symposium on acute respiratory diseases $^{1}$ have now been published. In addition to providing notable evidence of collaboration between microbiologist, epidemiologist, veterinary surgeon, paediatrician, and clinician, they also illustrate the value of bringing a variety of scientific disciplines to bear on a single objective. The opening chapters are rightly devoted to the rapidly expanding field of respiratory viruses, and the section is introduced by an important perspective review on the expansion of knowledge about these viruses in relation to the clinical syndromes they cause. From this beginning emphasis on the clinical aspects of the subject is never lost throughout the length of the monograph. The more scientific chapters summarize, for instance, knowledge of the structure of viruses and methods for their identification, thus augmenting the main clinical purpose of the symposium. The section on epidemiology illustrates well that difficulties experienced by the clinician in interpreting survey data are in large part a reflection of our still incomplete knowledge and imperfect laboratory methods. The comparative study of viral and mycoplasma infections in animals both broadens the scope of the review and may be essential for a proper understanding of the experimental work in this field.

Mycoplasms are being identified as an increasingly important cause of acute respiratory disease. The great volume of recent information about their biological properties and clinical manifestations has been distilled and can be found in this monograph as a comprehensible summary. The role of bacteria in acute respiratory disease may make less

1 College of Pathologists (1968). Acute Respiratory Diseases Symposium. Edited by D. A. J. Tyrrell (7. clin. Path., 1968, 21, Suppl. 2). exciting reading because the subject is a more familiar one, but we cannot afford complacently to underestimate their importance, of which there is a continual reminder in the persisting mortality figures. These deaths due to bacterial respiratory infections continue in spite of the wide range of antibiotics theoretically available for their treatment.

Many other problems of acute respiratory diseases are discussed in this symposium, including the possible role of viruses and bacteria in acute exacerbations of chronic bronchitis, respiratory damage due to inhaled metals, the characteristic changes due to immunological damage caused by external allergens, and the physiological consequences of such diseases.

Perhaps the greatest value of the symposium is to demonstrate the rapid and important progress being made in a number of widely different disciplines, which are now converging on to some of the problems of chest disease. The monograph should make salutary reading for those who have mistakenly grown to believe that the specialty of chest disease is finished now that tuberculosis has been conquered. Moreover, this symposium, having limited its scope strictly to the subject of acute respiratory disease, only scratches at the surface of the problems in the whole field of chest disease now awaiting study.

\section{Progress in Anaesthesia}

A World Congress of Anaesthetists takes place once every four years. The fourth was held a few weeks ago in London and was attended by several thousand anaesthetists from all over the world. Nothing smaller than the Festival Hall complex of buildings would have sufficed to accommodate it. The scientific proceedings at the congress gave a good general picture of the growing points in this rapidly expanding field of medicine.

The content of the training of anaesthetists is still of widespread concern, though it must inevitably be linked to the social and economic conditions of each country. There is thus understandably little international unanimity beyond the fact that specialized training is necessary. Even in countries which are, anaesthetically speaking, more advanced, such as the United Kingdom, the U.S.A., and Scandinavia, the emphasis ranges widely from the straightforward clinical experience in Britain to the more theoretical and research aspects of the subject in the U.S.A. The world-wide shortage of anaesthetists was underlined, and of the several causes, other than financial return, the failure to interest the undergraduate student appears to be an important one. Anaesthesia, however, is still believed to be an essential ingredient in undergraduate instruction, not so much for teaching the techniques of anaesthetizing patients as for the greater understanding it gives of the part it plays in surgical treatment and also the many ways in which the anaesthetist's skill is applied to other fields of medicine. The broadening of the anaesthetist's field of work of from what used to be exclusively the operating-theatre to embrace a wide range of disorders in other branches of medicine is nowhere better illustrated than in his contribution to intensive therapy. ${ }^{1}$ The symposium on this subject was largely devoted to questions of architectural design of the units, and of management and operational 
policy, though there was little agreement on the extent to which the anaesthetist should be involved in the overall management of these units. While economy and practicality suggest that intensive care units should be sited near similar areas such as postoperative recovery rooms, separation between the groups of patients seems necessary if crossinfection and other undesirable results are to be avoided. Within the field of respiratory intensive care infants present special problems. The need for humidification, the difficulty of maintaining long-continued artificial ventilation, and the vexed question of tracheal intubation versus tracheostomy in infants were debated.

A little removed from the clinical sphere but of great potential importance for the future, much attention was devoted to the pharmacokinetics of anaesthetic drugs and to the applications of the computer to anaesthetic work. The broad mechanisms by which inhaled anaesthetics are distributed to tissues of different sorts is now well understood, and the importance of the solubility of the anaesthetic in blood in determining the speed of both induction and recovery is clear. The influence of ventilation on the uptake of inhaled anaesthetics is now well known. Blood volume is also an important factor. Thus in hypovolaemia arterial tensions are higher, but elimination is quicker, than in normovolaemia. Newer studies show, for example, the influence of depression of the cardiac output in apparently potentiating inhaled anaesthetics by tending to raise the arterial tension of the anaesthetic. The rate of uptake of volatile anaesthetics in infants is not necessarily the same as that for adults, nitrous oxide, for example, being taken up much more rapidly. The difference appears to be due to the relatively large cardiac output in the newborn. Certain halogenated anaesthetics formerly regarded as highly stable do in fact undergo biochemical transformation. Thus labelled bromine is released from halothane and accumulates in the body to be excreted in the urine.

Computers offer many possibilities to the anaesthetist. Apart from the handling of clinical records, at least one application which will be welcomed is the immediate transformation of data from monitors into physiological quanta. The matching of the data against a pre-set programme may well lead to the era of computer-assisted anaesthesia, and perhaps even to computer-controlled anaesthesia. Computers will also help in the study of pharmacokinetics and in the visual demonstration, for teaching purposes, of complex physiological systems. An unusual symposium in a congress of this sort was on communication in anaesthesia. This was sponsored by the Council for International Organizations of Medical Sciences and discussed the barriers which exist between specialists of different sorts within medicine, between the anaesthetist and the scientist, between teacher and student, and, perhaps most important of all, the barrier of language between specialists of different countries. Already these barriers are falling as anaesthetists emerge from their hitherto rather restricted technical sphere, for their interest is expanding rapidly both from the bedside to the basic science laboratory and from the operating-theatre into almost every other branch of medicine. A serious attempt to break down the barrier of language is the construction of a vocabulary of anaesthetic technical terms giving their precise definitions and their equivalents in at least one or two of the major world languages. This is already far advanced and will do much to eliminate many of the embarrassments both of translation of manuscripts and of communication at congresses.

\footnotetext{
1 Intensive Care, B.M.A. Planning Unit Report No. 1, 1967. British
} Medical Association.
The congress showed that, though the changes in day-today work of the clinical anaesthetist have not been dramatic since the last congress four years ago, the understanding of his work and its influence on the patient has progressed greatly. Research has been intense on many fronts. Its influence on clinical use is sure to become apparent soonmuch of it before the next congress due to be held in 1972 in Tokyo.

\section{Tinea Pedis}

Large numbers of any population of shoe wearers have abnormalities of the skin of their toe clefts, but most of them have no recognized pathogen there. In some the skin will show under Wood's light the pink fluorescence of erythrasma, a few may carry candida, and occasionally a bacterial infection appears to be responsible for the skin changes. The term tinea pedis, or athlete's foot, should be strictly reserved for those infected with a dermatophyte fungus.

The prevalence of this condition in the general population is unknown, and a survey of a true representative sample would present considerable difficulties. But much is known of the epidemiology of tinea pedis in different communities, especially from the work of Mary P. English and her associates in Bristol. The latest of her series of investigations-a study of tinea pedis in patients attending a chiropody clinic-is reported with $\mathrm{Mr}$. J. Turvey in this issue of the B.M.F. at page 228 . They found that $23 \%$ of $161 \mathrm{men}$ and $4 \%$ of 98 women were infected, two-thirds of the cases being due to Trichophyton mentagrophytes var. interdigitale $(=T$. interdigitale). From this and earlier ${ }^{1}$ studies it seems likely that the difference between the sexes is due largely to differences of exposure to infection and partly to differences in footwear. Experimental evidence confirms that an inherent difference in susceptibility is improbable. ${ }^{2}$ We know that communities of boarding-school boys, long-stay hospital patients, and coal miners if they use pit-head baths all have high levels of infections-up to $60 \% .^{34}$ Boys at day schools are more likely to have tinea pedis if they are frequent swimmers at public baths. Dermatophyte fungi have been isolated from the floors of swimming-baths and showerrooms $^{5}$ and from socks even after laundering. ${ }^{3}$ The routes of transmission are in little doubt, and in this context the family bathroom should not be forgotten.

Though this condition is often trivial and may be selfhealing, it is right to try to reduce the level of infection by preventive methods. Exclusion of infected swimmers from public baths is completely impracticable. Foot-baths are useless (or worse), but frequent hosing down of walk ways and shower-room floors is easy and of proved value. The floors of shower-baths are most heavily infected immediately after use. ${ }^{5}$ It would seem logical, therefore, to incorporate in them a separate horizontal jet, set low to sweep the floor automatically after each person has passed. It is unrealistic to expect the general public to modify their washing habits or

\footnotetext{
1 English, M. P., Brit. med. 7., 1961, 1, 1086.

Rosenthal, S. A., and Baer, R. L., f. invest. Derm., 1966, 47, 568.

English, M. P., Wethered. R. R., and Duncan, E. H. L., Brit. med. F.,

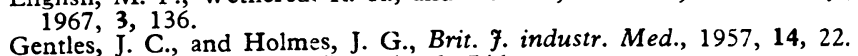

5 Gentles, J. C., Brit. med. F., 1957, 1, 746.
} 